\title{
Filosofia da Macumba: a sacralização do corpo do negro na poética de Solano Trindade
}

\author{
Philosophy of Macumba: the sacralization of the body of the black man in the \\ poetics of Solano Trindade
}

\author{
Bas'Ilele Malomalo*
}

Resumo: Esse trabalho analisa a quarta e quinta estrofes do poema "Macumba" de Trindade. Defende que esse poeta negro usa a estética poética, pautando-se nas religiões de matrizes africanas, para enfrentar o paradigma branco-racista que reduz o corpo negro à vadiagem. Trindade interpreta o corpo negro como um corpo sagrado e convida para a prática de uma política filosófica que valoriza a vida em todas suas manifestações.

Palavras-chave: Trindade; Macumba; Negro; Vida

Abstract: This work analyzes the fourth and fifth stanzas of the poem "Macumba" of Trindade. It argues that this black poet uses poetic aesthetics, based on the religions of African matrices, to face the white-racist paradigm that reduces the black man body to vagrancy. Trindade interprets the black man body as a sacred body and invites to practice a philosophical policy that values life in all its manifestations.

Keywords: Trindade; Macumba; Black; Life

\section{Palavras encantadas}

$\mathrm{Na}$ prática da filosofia de macumba que tenho praticado cada epigrafo é parte do texto e por isso faço questão de começar com esse poema da professora universitária e ativista do movimento negro, Lívia Natália, inserindo-o no texto:

\section{Da inutilidade da poesia (Para o Prof. Hélio Santos)}

63 jovens negros são mortos por dia.

23 mil jovens negros são mortos por ano.

Ao menos um morreu agora,

\footnotetext{
Docente no Programa de Mestrado Interdisciplinar em Humanidades, Instituto de Humanidades e Letras/Universidade da Integração Internacional da Lusofonia Afro-Brasileira (BA), líder do Grupo de pesquisa África-Brasil: Produção de conhecimento, Sociedade civil, Desenvolvimento e Cidadania Global; Email: basilele@unilab.edu.br
} 
Enquanto você lia este poema ${ }^{1}$.

Essas estrofes merecem ser tratadas pela necessidade que o sujeito que retratam, o homem negro, merecer outros olhares que sejam valorativos, como diria Guerreiro Ramos, investigar 'o negro desde dentro' ${ }^{2}$, para escapar dos olhares que tendem a coisificá-lo. Por isso, o seu corpo é tratado pelo pensamento branco-racista como território permitido para a execução quaisquer tipo de violência física e simbólica. A necropolítica ${ }^{3}$, que não tem somente o Estado como seu agente executor principal, mas toda sociedade euro-ocidental capitalista e racista, opera no sentido de decidir sobre a morte de vidas de pessoas negras.

Seguindo um dos passos da filosofia de macumba proposta por mim, sugiro contemplar a estética do poema de Solano Trindade, antes de prosseguir com outros passos que compõem o propósito desse texto. Vamos saborear a estética trindadiana presente no seu poema e se trata, com certeza, do primeiro passo da filosofia da macumba ${ }^{4}$. macumbizar desmacumbizando-se pelo belo.

1 MACUMBA $^{5}$

$2 \quad$ Noite de Yemanjá

Negro come acaçá

Noite de Yemanjá

Filha de Nanan

Negro come acaçá

Veste seu branco abebé

3 Toca o águe

O caxixi

O agogô

O gã

O engona

O ilu

O lê

O roncó

O run

O rumpi

\footnotetext{
${ }^{1}$ NATÁLIA, Sobejos do mar, p. 73.

${ }^{2}$ RAMOS, Introdução crítica à sociologia brasileira.

${ }^{3}$ MBEMBE, Necropolítica / Sobre el gobierno privado indirecto. Santa Cruz de Tenerife: Editorial Melusina.

${ }^{4}$ MALOMALO, Macumbização e desmacumbização, 2016.

${ }^{5}$ TRINDADE, Poemas antológicos, p. 76-77.
} 
$4 \quad$ Negro pula

Negro dança

Negro bebe

Negro canta

Negro vadia

Noite e dia

Sem parar

Pro corpo de Yemanjá

Pros cabelos de Obá

Do Calunga

Do mar

$5 \quad$ Cambondo sua

Mas não cansa

Cambondo geme

Mas não chora

Cambondo toca

Até o dia amanhecer

6 Mulata cai no santo

Corpo fica belo

Mulata cai no santo

Seus peitos ficam bonitos

7 Eu fico com vontade de amar...

Tenho sugerido, na filosofia de macumba, que a construção de um trabalho intelectual negro deve se pautar nas bibliotecas negras, africanas e afro-diaspóricas, e não negras antirracistas. Os materiais que devem auxiliar para construção de um vôo filosófico podem ser extraídos para construção de um voo filosófico podem ser extraídos das bibliotecas acadêmicas e não acadêmicas, salvaguardando a cultura negra sempre como o lugar de partida desse fazer filosófico.

Tendo em conta o material primário que disponho, um bem artístico negro para analisar, fundamento minhas interpretações filosóficas nas obras de Mveng ${ }^{6}$, Bilolo Ntumba ${ }^{8}$, Faik-Nzuji ${ }^{9}$, Sodré ${ }^{10}$ e Bourdieu ${ }^{11}$. As propostas sociológicas desse último autor

\footnotetext{
${ }^{6}$ MVENG, Problematique d'une estétique negro-africaine, 2014; MVENG, L'art d'Afrique noire: liturgie cosmique et langage religieux, 1974.

${ }^{7}$ BILOLO, Les cosmo-théologiques philosophiques de l'Égypte antique: Problématiques-prémisses hermenêutiques-etproblèmes majeurs, 1986.

${ }^{8}$ NTUMBA, Le réel comme procès multiforme: pour une philosophie du Nous processuel, englobant et plural, 2014.

${ }^{9}$ FAIK-NZUJI, Arts africains: Signes et symboles, 2000.
} 
são necessárias pelo fato de auxiliar a tratar toda obra de arte como um bem cultural produzido socialmente e que obedece às regras de uma economia simbólica. Em outras palavras, toda arte retrata as relações de poder entre os agentes envolvidos na luta no campo particular de sua produção. Interpreto o poema de Trindade levando em conta os mecanismos do racismo mundial e brasileiro ${ }^{12}$; os debates filosóficos e sociológicos da intelectualidade negra sobre as estratégias de morte impostas ao corpo do homem negro ${ }^{13}$.

Outros autores citados anteriormente trabalham diretamente com a cultura negra e filosofia africana, continental e diaspórica, que é parte desse sistema cultural. Está presente nesse trabalho a ideia de uma hermenêutica do primeiro grau e segundo grau de Ntumba ${ }^{14}$. No caso, parto do princípio de que o poema "Macumba" de Trindade é uma obra filosófica do primeiro grau e minhas interpretações constituem uma filosofia da segunda instância que engajam somente o seu autor.

Aproprio-me de Faik-Nzuji ${ }^{15}$, Mveng ${ }^{16}$ e Sodré ${ }^{17}$ a ideia de que os bens da cultura negra são elementos, gestos, ações, signos e símbolos a ser decifrados filosoficamente. E digo com Bilolo ${ }^{18}$, decifrados sempre, a partir de uma hermenêutica valorativa e não pejorativa e racista. Nei Lopes ${ }^{19}$ e Kileuy e Oxaguiã ${ }^{20}$ me possibilitam estabelecer o diálogo entre os textos acadêmicos e não acadêmicos, tendo a cultura negra como centro da gravitação filo-sociológica.

Divido esses textos em quatro partes: "Palavras para o encantamento" que é a introdução; o "Negro devoto é um auxiliar da macumba" e "O corpo sacro-profano do Negro devoto" que compõem o desenvolvimento da minha argumentação; e as "Palavras do recomeço" que é a minha conclusão. Com isso, defendo que a liberdade da escrita é uma

\footnotetext{
${ }^{10}$ SODRÉ, A verdade seduzida: Por um conceito de cultura no Brasil, 2005; SODRÉ, Pensar nagô, 2017.

${ }^{11}$ BOURDIEU, Les règles de l' art: Genèse et structure du champ littéraire, 1998.

${ }^{12}$ BERNARDINO-COSTA; MALDONADO-TORRES; GROSFOGUEL (Orgs.). Decolonialidade e pensamento afrodiaspórico, 2018; MBEMBE, Crítica da razão negra, 2014; MOORE, Racismo e sociedade: novas bases epistemológicas para entender o racismo, 2007.

${ }^{13}$ Foco nesse texto no homem negro, pois essa é a pista dada pelos versos que estou analisando. Entre outros textos que asseguram minhas reflexões ver FLAUZINA, Corpo negro caído no chão: O sistema penal e o projeto genocídio do Estado brasileiro, 2017; FLAUZINA; VARGAS. Motim: Horizontes do genocídio antinegro na Diáspora, 2017; PESSANHA; NASCIMENTO, Necropolítica: Estratégia do extermínio do corpo negro, 2018; NASCIMENTO, O Genocídio do Negro Brasileiro: Processo de um Racismo Mascarado, 1978.

${ }^{14}$ NTUMBA, Le réel comme procès multiforme: pour une philosophie du Nous processuel, englobant et plural, 2014.

${ }^{15}$ FAIK-NZUJI, Arts africains: Signes et symboles, 2000.

${ }^{16}$ MVENG, Problematique d'une estétique negro-africaine, 2014.; MVENG, L'art d'Afrique noire: liturgie cosmique et langage religieux, 1974.

${ }^{17}$ SODRÉ, A verdade seduzida: Por um conceito de cultura no Brasil, 2005; SODRÉ, Pensar nagô, 2017.

${ }^{18}$ BILOLO, Les cosmo-théologiques philosophiques de l'Égypte antique: Problématiques-prémisses hermenêutiqueset-problèmes majeurs, 1986.

${ }^{19}$ LOPES, Enciclopédia brasileira: Diáspora africana, 2004; LOPES, Dicionário escolar afro-brasileiro, 2006.

${ }^{20}$ KILEUY; OXAGUIÃ. O Candomblé bem explicado (nações bantu, ioruba e fon), 2009.
} 
liberdade filosófica e isso implica uma ruptura com formas tradicionais de organizar os textos ${ }^{21}$.

\title{
O corpo sacro-profano do negro devoto
}

\author{
Negro pula \\ Negro dança \\ Negro bebe \\ Negro canta \\ Negro vadia \\ Noite e dia \\ Sem parar \\ Pro corpo de Yemanjá \\ Pros cabelos de Obá \\ Do Calunga \\ Do mar" \\ (Solano Trindade)
}

Iniciar uma argumentação com um epigráfo, quando possível, é não somente um recurso estético, mas igualmente uma forma de organizar o discurso científico dentro da epistemologia da macumba ${ }^{22}$.

Quando lido do ponto de vista da totalidade do todo poema, no quarto estrofe, o Negro devoto continua a ser o destaque: ele pula, dança, bebe, canta e vadia durante um tempo indetermino ("Noite e dia"; "Sem parar") não por qualquer motivo ou qualquer personagem, mas para duas orixás: Yemanjá e Obá. O verbo "vadiar” constitui a ação principal que comanda as outras: "pular", “dançar” e "beber”. Esses três formam o que se chama de vadiagem.

Interessante é perceber que algumas ações que em outros contextos seriam vistas pelo olhar racista vigente como fatos sociais a serem reprimidos e que levariam a morte de seus autores quando fossem negros, são recuperados positivamente pelo poeta. Estou me referindo às ações como "pular”, “dançar”, "beber” e "vadiar" que, no contexto brasileiro, carregam representações negativas contra o negro, visto este como o bêbado ou vagabundo. Preconceitos e estigmas raciais que remontam desde os tempos da colonização

\footnotetext{
${ }^{21}$ MALOMALO, Bioepistemolologia do Ntu: Meu(s) diálogo(s) com Dagoberto José Fonseca, 2018; MALOMALO; FERREIRA (Orgs.). Intelectualidade coletiva negra: memórias, educação e emancipação, 2018.

${ }^{22}$ Ibidem; Ibidem.
} 
e escravidão ${ }^{23}$ e que têm por função cometer o genocídio contra o corpo negro e sua cultura ${ }^{24}$.

Através do recurso poético, Solano Trindade tenta quebrar essas representações pejorativas e racistas. Inverte-as política e poeticamente. Busca na cosmovisão africana, onde o profano e o sagrado dialogam permanentemente, novos recursos para retratar a imagem do novo negro ${ }^{25}$. Os gestos tidos por profanos e sacrilégios, são transformados em sagrados. Tudo se passa como se houvesse um processo de sacralização do profano e a profanação do sagrado. No meio de tudo isso é o corpo do Negro devoto que ocupa a cena. Aqui como em outros momentos do seu poema se consume o que identifico com Mveng ${ }^{26}$ como liturgia cósmica da arte africana.

A dimensão litúrgica da Arte negra inaugura a celebração da vitória da Vida sobre a Morte pela unificação do destino do homem e o destino do mundo. Eis a razão pela qual a Arte negra não é, como a Arte ocidental, um "mimêma tou pantos", uma reprodução do universo. Ela é, ao contrário, uma recriação do universo. Nos ritos africanos, a escultura, a pintura, a arte decorativa, os ornamentos, a música, a dança, sopram nos elementos do cosmos a plenitude da alma humana, e os elementos do cosmos se tornam o corpo humano. Os ritos de iniciação realizam a perfeição dessa dimensão litúrgica da nossa arte. O homem encontra-se nele pelos todos gestos da criatividade artística. Ele fala, recita, declama, improvisa, canta, escultura, desenha, decora, cria ornamentos, adornos, vestimentas; aprende a construir a sua morada, e celebra todo isso através de uma longa paixão onde todos seus aliados, na natureza, juntam-se a ele para dar o supremo golpe à Morte $^{27}$.

Solano Trindade vai mais longe e transforma a vadiagem, que tem o corpo negro como suporte, em sagrado. O corpo do Negro devoto "vadia”, isto é, pula, dança e bebe age para o "corpo de Yemanjá" e os "cabelos de Obá”. Yemanjá continua a ocupar o espaço maior nessa liturgia secular ou política ${ }^{28}$, pois é evocada duas vezes no segundo estrofe do poema e no quarto, uma vez que o mar remente à sua moradia: ela é tida como a rainha do mar.

\footnotetext{
${ }^{23}$ MOURA, Dialética radical do Brasil negro; MOORE, Racismo e sociedade: novas bases epistemológicas para entender o racismo; BENTO, Branqueamento e branquitude no Brasil, p. 25-58.

${ }^{24}$ FLAUZINA, Corpo negro caído no chão: o sistema penal e o projeto genocídio do Estado brasileiro, 2017; FLAUZINA, Motim: Horizontes do genocídio antinegro na Diáspora, 2017; PESSANHA, Necropolítica: Estratégia do extermínio do corpo negro, 2018; NASCIMENTO, O Genocídio do Negro Brasileiro: Processo e um Racismo Mascarado, 1978.

${ }^{25}$ FERNANDES, A integração do negro na sociedade de classes, 1978.

${ }^{26}$ MVENG, Problematique d'une estétique negro-africaine, 2014.

${ }^{27}$ Ibidem, p. 10-11.

${ }^{28}$ RIVIÈRE, As liturgias políticas, 1989.
} 
Ao descrever Iamanjá no Brasil, Kileuy e Vera de Oxaguiã ${ }^{29}$ escrevem que ela transformou-se na "senhora dos mares", talvez devido à grandeza oceânica do país que lhe acolheu, mas o autor afirma também que ela é tida como a rainha dos lagos, das lagoas e da junção do rio com o mar, por isso é chamada de "odô-iyá", "a mãe dos rios”. Não só isso. Ela é reconhecida como a "mãe dos peixes" e a "mãe de todos os orixás", "aquela que recebe e acolhe com amor mesmo os que não foram gerados por ela, mas que foram entregues a seus cuidados" ${ }^{30}$; ela é a "mãe de todas as cabeças”, a mãe de todos os iniciados.

Sua importância é tão grande que todos os iniciados, mesmo aqueles que não a têm como seu orixá principal, possuem uma ligação especial com ela, pois ao ser considerada a mãe de todos os orixás, torna-se avó de todos! E todas as pessoas iniciadas no candomblé, em um período de sua evolução religiosa, terão que assentar Iemanjá porque ela faz parte da corte dos orixás que reinam em todas as cabeças. Assim, ninguém merece mais do que ela o poderoso título de a "Grande Mãe" 31.

Iemanjá é tida como filha de Nanã. Esta é considera a orixá mais velha, a ancestral; orixá da lama a partir da qual, em alguns mitos iorubanos, o ser humano foi moldado, criado $^{32}$

Em vez de uma necropolítica para com o corpo negro ${ }^{33}$, de tratar o homem negro como homo saccer, parafraseando Agamben ${ }^{34}$, sujeito cuja vida deve ser eliminada pelo fato de ter nascido negro, Trindade convida a sociedade a tratá-lo numa perspectiva da “potência de vida-ntu-axé-kalunga” e “política de vida-ntu-axé-kalunga”. Ou seja, uma vida humana que deve ser respeitada por si. Uma vida cuja dignidade deve ser valorizada por pertencer a comunidade cósmica. Quer dizer que comunidade do universo-natureza e do sagrado-ancestral das quais a comunidade-universo-natureza e comunidade-bantu (ser pessoa) emanam e participam solidariamente. O slogan "vidas negras importam" nesse contexto deve ser interpretado do ponto de vista da ética biocêntrica ${ }^{35}$ que exige que cada vida seja respeitada por si só. Ademais a sua compreensão filosófica nos obriga compreender cada comunidade de vida na sua interdependência solidária com outras formas de vida.

\footnotetext{
${ }^{29}$ KILEUY; OXAGUIÃ, O Candomblé bem explicado (nações bantu, ioruba e fon), p. 296-297.

${ }^{30}$ Ibidem, p. 297.

${ }^{31}$ Ibidem.

${ }^{32}$ PRANDI, Mitologia dos orixás, 2001.

${ }^{33}$ MBEMBE, Necropolitica / Sobre el gobierno privado indirecto, 2011.

${ }^{34}$ A GAMBEN, Meios sem fim: Notas sobre a política, 2015.

${ }^{35}$ NAKOULIMA, A crise ecológica como exigência de um novo paradigma, 2012; THÉSÉE, L’interculturel en environnement: Rencontre de la justice sociale et de la justice environnementale, 2008.
} 
$\mathrm{Na}$ perspectiva da filosofia de Iemanjá, a ética biocêntrica africana nos convida a praticar a ética do cuidado, do acolhimento e do amor para todos os entes que formam a comunidade-ntu-axé-kalunga: a potência da vida, a força vital ou a vida-energia-emplenitude. Ou seja, como nos lembra Mveng ${ }^{36}$ celebrar com a arte negra a vitória da Vida sobre a Morte.

O calunga evocado no poema de Trindade nos introduz na complexidade dos saberes africanos e afro-brasileiros para o diálogo intercultural:

Termo usado no Brasil em várias acepções:

$\mathrm{Na}$ umbanda, nomeia cada um dos integrantes da falange de seres espirituais que vibram na linha de Iamanjá. Em linguagem mais geral, designa qualquer boneco pequeno; camundongo; pessoa de pequena estatura principalmente por ser aleijada da coluna vertebral; indivíduo de cor preta; cada um dos habitantes da comunidade dos Calungas, em Góis; falar banto da região do Triangulo Mineiro e do alto Paraiba; cada um dos bonecos que fazem parte do cortejo dos maracatu; o mar; o ceú; a morte. Etimologicamente: a origem etimológica do vocabulário está no multilinguístico banto kalunga, que encerra a ideia de grandeza, imensidão, designando Deus, o mar, a morte. Segundo A. Costa e Silva, entre alguns povos bantos, kalunga representada por uma boneca sempre guardada em um curso de água, é símbolo de força e fonte de poder político. No Brasil, o ícone antropomorfo (o iteque, a estatueta, representativo de qualquer entidade divinizada) passou a se chamar "calunga". Ver, por exemplo, a "calunga de maracatu". O termo, portanto, se estendeu, formando outras acepções $^{37}$.

Quero explorar, primeiro, o significado do Calunga na sua ligação ao mar, visto este como morada de Yamanjá. Pois é nessa direção que o Negro devoto faz dançar o seu corpo.

Iamanjá representa a água que refresca e dá a vida à terra, que ajuda na procriação e na geração de novos seres. A água que apascenta e que acalma; a que cai do orum e depois retorna, para descer novamente em forma de chuvas - a "água divina e sagrada” de Olorum [divindade suprema iorubana $]^{38}$.

A água é, para os povos africanos, sinal da vida-ntu-axé-kalunga. Auxilia na procriação e regeneração de seres. Na filosofia do Egito antigo, nos alerta Obenga ${ }^{39}$, ao

\footnotetext{
${ }^{36}$ MVENG, $L^{\prime}$ art d'Afrique noire: liturgie cosmique et langage religieux, p. 10

${ }^{37} \mathrm{NEI}$, Enciclopédia brasileira: Diáspora africana, p. 556 (grifo do autor).

${ }^{38}$ KILEUY; OXAGUIÃ, O Candomblé bem explicado (nações bantu, ioruba e fon), p. 297.

${ }^{39}$ OBENGA, La philosophie africaine de la période pharaonique, 2780-330 avant notre ère, 1999.
} 
lado de outros elementos da natureza, ar e fogo, a água é a força vital, o arkhê africano ${ }^{40}$ a partir da qual tudo que existe emana.

Faik-Nzuji, estudiosa congolesa, na mesma perspectiva traduz a visão dos povos da região do Kongo com esses termos:

O universo se concebe assim como uma totalidade de uma rede de relações ininterrompidas ou circular, chocam-se ou trocam energias quentes e frias, machas e fêmeas, positivas e negativas, fortes e fracas, etc. Essas diferentes polaridades traduzem a natureza de todos os seres e todas as coisas criadas e determinam seu caráter em todas as circunstâncias onde se manifestam. Essa concepção é representada pelo símbolo de Kalunga ${ }^{41}$.

Kalunga, explica a mesma estudiosa congolesa, traduz a ideia do sagrado.

Os Valucazi, Tshokwe e Baluunda que habitam no leste de Angola, centrosul do Congo-Kinshasa e nordeste chamam esse símbolo de Kalunga [...]. Esse termo forma o campo léxico-semântico do "sagrado" e nomes designando "Deus". O símbolo de Kalunga representa o Ser primordial, o infinito, uma "Coisa sem começo nem fim" e que contém em si todas as Criaturas ${ }^{42}$.

Faik-Nzuji ${ }^{43}$ explica o símbolo de Kalunga afirmando que o pequeno signo em cima representa Kalunga o Criador ele mesmo; o pequeno signo abaixo representa o homem; o pequeno círculo à esquerda representa o sol e o semi-círculo à direita representa a lua; os seis signos inscritos na linha vertical central representam as gerações que precedem ao indivíduo e que o ligam ao seu Criador.

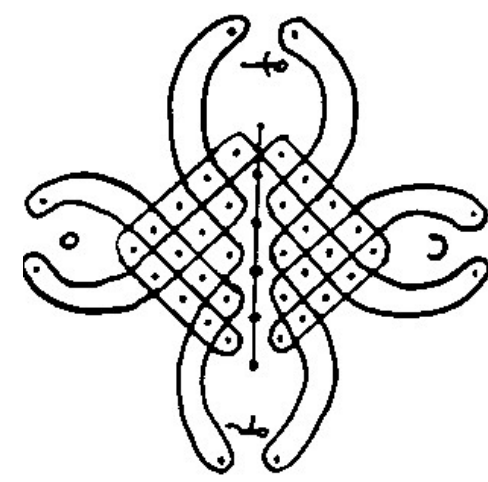

Kalunga ou símbolo de infinito ${ }^{44}$

\footnotetext{
${ }^{40}$ SODRÉ, O pensar nagô, 2017.

${ }^{41}$ FAIK-NZUJI, Arts africains: Signes et symboles, p. 30.

${ }^{42}$ Ibidem.

43 Ibidem.

${ }^{44}$ FAIK-NZUJI, Arts africains: Signes et symboles, p. 30.
} 
Para a autora, a linha vertical, no centro, marcada de seis pontos, aponta a estrada que leva a Deus. Os pontos inscritos nos pequenos quadros representam as criaturas de todas as espécies que existiram, existem e a vir. Esses pequenos quadros estão moldados por uma linha continua que as engloba e volta sobre ela mesma. Não tem nem início nem o fim: é o infinito, a eternidade. Os seis pontos inscritos na linha vertical representam as gerações que nos ligam à origem. O desenhar o símbolo Kalunga é, em geral, acompanhado de um recital mítico explicando por que o sol aparece cada dia, porque a lua volta cada vinte e oito dias e porque o ser humano conhece a morte ${ }^{45}$.

O Negro devoto de Solano é também devoto de Obá. Divindade do rio do mesmo nome, ela é um orixá feminino energético e fisicamente mais forte que muitos orixás masculinos. Era uma das esposas do Xângo e teria perdido uma das orelhas na batalha com uma de suas rivais, a Oxum. A sua dança é guerreira: ela brande um sabre com uma das mãos e leva um escudo na outra ${ }^{46}$.

A interpretação de Odé e Oxaguiã sobre Obá, para mim, é mais ousada e apaixonante do que a anterior.

Obá (obà) é uma divindade ioruba feminina, de idade avançada, guerreira poderosa, com um temperamento forte, e também uma grande feiticeira. $\mathrm{Na}$ Nigéria, um rio caudaloso e perigoso demostra bem o caráter irrequieto desta belicosa iyabá e a homenageia, levando seu nome. A sua importância no cerne da religião é conseguir comprovar a força da mulher e mostrar que quando ela vai à guerra é para vencer! Em conjunto com o homem, pode prover sua casa e seu proveito de alimentos. Ela mostra que, na luta diária, os dois sexos participam de batalhas vencidas instantaneamente ou que perduram por muito tempo. Mostra também que com a perseverança e coragem elas serão debeladas incontestavelmente. A mulher, geralmente, é quem produz e consegue um elemento para vencê-las! ${ }^{47}$

No que diz respeito ao arquétipo de seus filhos e filhas, Pierre Verger registra o seguinte:

O arquétipo de Obá é das mulheres valorosas e incompreendidas. Suas tendências um pouco viris fazem-nas frequentemente voltar-se para o feminismo ativo. As suas atitudes militantes e agressivas são consequências de experiências infelizes ou amargas por elas vividas. Os seus insucessos devem-se, frequentemente, a um ciúme um tanto mórbido. Entretanto, encontram geralmente compensação para as frustrações sofridas em

\footnotetext{
${ }^{45}$ Ibidem.

${ }^{46}$ VERGER, Orixás: Deuses iorubas na África e no novo mundo, 2002.

${ }^{47}$ KILEUY; OXAGUIÃ, O Candomblé bem explicado (nações bantu, ioruba e fon), p. 285.
} 
sucessos materiais, onde a sua avidez de ganho e o cuidado de nada perder dos seus bens tornam-se garantias de sucesso $^{48}$.

Que filosofia africana os elementos levantados por Kileu e Oxaguiâ e Verger da figura de Obá nos proporciona?

Uma das primeiras interpretações que faço é que, para Solano Trindade, a vida de um devoto dos orixás não é só flores, mas está repleta também de atritos, incompreensões, sofrimento. Todavia, como o Negro devoto se confia aos cuidados da "Guerreira poderosa", "Grande feiticeira”, ele tem a capacidade de resistir e vencer os obstáculos da vida cotidiana. E pode se perceber aqui que macumba como feitiço tem outro sentido: a confiança na Grande orixá, ancestral do ser humano, da natureza e de todos os orixás com intuito de resolver problemas existências.

Outra pista de leitura é levar em conta os princípios de solidariedade e complementaridade entre homens e mulheres em suas lutas cotidianas, familiares e políticas. Intelectuais africanas, como Amadiume ${ }^{49}$ e Oyewumi ${ }^{50}$, por exemplo, não veem nenhum problema para que homens africanos participam nas batalhas de mulheres. Tratase, no caso desse trabalho, da elaboração conjunta de estratégias de resistência contra a necropolítica voltada contra a população africana continental e diaspórica. Ou seja, faz-se necessário que homens negros e mulheres negras se unem entre si e com outras raças para exigir o direito de existir ${ }^{51}$.

Ficou claro que o Negro devoto é filho de Iamanjá e Obá. A sua vadiagem consiste em cultuar essas duas mulheres. O quinto estrofe nos revela que ele é um ogã. O que ratifica a tesa da sacralização do seu corpo. Ou seja, se ele vadia é para suas órixas. Diga-se de passagem, trata-se de uma vadiagem sagrada.

\section{Negro devoto é um auxiliar da macumba}

Cambondo sua

Mas não cansa

Cambondo geme

Mas não chora

Cambondo toca

Até o dia amanhecer

(Solano Trindade)

\footnotetext{
${ }^{48}$ VERGER, Orixás: Deuses iorubas na África e no novo mundo, p. 187.

${ }^{49}$ AMADIUME, Reiventing Africa: Matriarchy, religion and culture, 2001.

${ }^{50}$ OYEWUMI, The invention of Woman: Making na african sense of wester gender discourses, 1997.

${ }^{51}$ MALOMALO, Retrato dos brancos/as antirracistas feito do ponto de vista de uma educação macumbista, 2017.
} 
Na quinta estrofe, Trindade continua destacando o Negro devoto que, desta vez, é retratado como "Cambondo". A pesquisa feita traz alguns significados deste termo. O primeiro é o que encontrei num dicionário português online:

\section{Significado de Cambondo.}

Adj. (quimbundo kambanda) Amancebado. s.m. 1 Amásio, amigo. 2 Acólito do oficiante, na macumba.

Definição de Cambondo. Classe gramatical: Substantivo masculino e Adjetivo.

Separação das sílabas: cam-bon-do. Plural: cambondos ${ }^{52}$.

Nei Lopes ${ }^{53}$ escreve com a grafia Cambono que é, para ele, o auxiliar de pai-desanto, na umbanda. Em Roger Bastide ${ }^{54}$, encontramos o termo Cambône, que significa assistente dos sacerdotes ou dos médiuns na cabula ou na macumba.

O Cambono trindadiano é um ser humano real, vivo, histórico. Tocando o candomblé/umbanda, as músicas e danças sagradas, ele sua; ele cansa; ele geme; ele chora; ele toca até o dia amanhecer. É um sujeito resistente, forte e devoto. É um ogã (em iorubá), xicaringome/xicarangoma ou tata cambono, um oficiante de macumba, tocador dos tambores sagrados das religiões afro-brasileira enunciado no segundo estrofe do poema.

Toca o águe
O caxixi
O agogô
O gã
O engona
O ilu
O lê
O roncó
O run
O rumpi

Essa é a explicação que nos fornece Kileuy e Oxaguiã sobre os ogãs:

São autoridades masculinas, de posto hierárquico abaixo do/a sacerdote/sacerdotisa, e seus auxiliares diretos, assim denominado pelos

\footnotetext{
${ }^{52}$ DICIO, Dicionário português online. (grifo meu)

${ }^{53}$ LOPES, Enciclopédia brasileira: Diáspora africana, 2004.

${ }^{54}$ BASTIDE, As religiões africanas no Brasil: Contribuições a uma sociologia das interpretações de civilizações, p. 558.
} 
ioruba. Na nação fon recebem o nome de runtó/huntó e na nação bantu são chamados xicaringome/xicarangoma ou tata cambono. Estes homens [...] não entram em transe $[. . .]^{55}$.

Tambores são instrumentos musicais sagrados que conecta as três comunidades-devida (comunidade-do-sagrado-ancestral, comunidade-universo-natureza e a comunidadedos-bantu), que é a comunidade-ntu-axé ou comunidade-kalunga. O tambor coloca em comunhão o mundo visível (Aiyê) com o mundo invisível (Orun). Nesse processo ritualístico o ogã é um sujeito importante dentro da comunidade de fé, o terreiro, nos momentos ritualísticos e fora deles.

O Negro devoto, o ogã, toca “Até o dia amanhecer” é o último verso do quinto estrofe que constitui um quiasmo com o primeiro verso que abre o poema: "Noite de Iemanjá”. Interessante entender é o cruzamento destes dois versos através das palavras "Noite" e "Dia" que aponta para o cumprimento de um ciclo histórico-cósmico: Kalunga, o infinito. Ou seja, o corpo do homem negro de Trindade é um corpo sagrado. A sua luta envolve forças visíveis e invisíveis. Por isso, é permitido cantar a vitória do amor, da vida sobre a morte, as forças maléficas que regem as sociedades racistas.

\section{Palavras do recomeço}

O poema de "Macumba" de Trindade me levou a praticar o que se chama de filosofia cultural ou hermenêutica da macumba na Filosofia africana. É em si uma peça filosófica pela sua estrutura e densidade pedagógica.

Elegi para a análise filosófica da segunda instância, o quarto e quinto estrofes. Estes me levam a afirmar que o corpo do homem negro, nesse poema, é sacralizado e é sagrado. Para tanto, Trindade faz uso de alguns recursos estéticos servindo-se da filosofia africana presente nas religiões de matrizes africanas.

O que Prandi diz do povo ioruba pode se estender a outros povos africanos e confirma a nossa tesa da sacralização da vida cósmica em geral e da vida humana em particular:

Os iorubas acreditam que homens e mulheres descem dos orixás, não tendo, pois, uma origem única e comum, como no cristianismo. Cada um herda do orixá de que provém marcas e características, propensões e desejos, tudo como está relatado nos mitos. Os orixás vivem em luta uns contra outros, defendem seus governos e procuram ampliar seus domínios, valendo-se de todos os artifícios e artimanhas, da intriga dissimulada à guerra aberta e sangrenta, da conquista amorosa à traição. Os orixás alegram-se e sofrem,

\footnotetext{
${ }^{55}$ KILEUY; OXAGUIÃ, O Candomblé bem explicado (nações bantu, ioruba e fon), p. 60.
} 
vencem e perdem, conquistam e são conquistados, amam e odeiam. Os humanos são apenas cópias esmaecidas dos orixás dos quais descem ${ }^{56}$.

A sacralização do corpo do homem negro, no poema analisado, acontece quando Trindade reverte o paradigma branco-racista da vadiagem sobre o negro para atrelar esse termo às ações ritualísticas da comunidade de fé do seu personagem, o terreiro. Nesse paradigma africano, o negro trindadiano aparece como devoto de Iamanjá e Obá. Duas órixas femininas cujos elementos da ética e estéticas filosóficas nos convidam para a prática do cuidado, do amor e do acolhimento do outro que interpretei, em diálogos com outros textos das bibliotecas africanas e afro-brasileiras, como o convite à prática da ética biocêntrica assente na valorização do Real total, processual, global e multiforme ${ }^{57}$. Comunidade-vida-ntu-axé-kalunga que se manifesta na comunidade-do-sagrado-ancestral, comunidade-bantu e comunidade-universo-natureza ${ }^{58}$.

Nessa ótica toda vida tem o seu valor intrínseco. A necropolítica, que ameaça as vidas negras, especialmente do homem negro, pelas práticas do racismo e genocídio deve ser confrontada e superada pela implementação urgente da política filosófica do ntu-axékalunga por valorizar essa filosofia a vida na sua plenitude ou potência da vida. Macumba, levando em conta as duas partes analisadas do poema é um convite à celebração da vida sobre a morte. A última estrofe do poema de Trindade nos dá razão, quando o poeta grita: “Eu fico com vontade de amar...”. Quer dizer, a superação da crise planetária que afeta de forma cruel a vida de pessoas negras, exige a mudança de paradigma do ódio e do racismo para um outro paradigma do amor-macumba. Encantamento pelo Outro que é sempre sagrado.

\section{Referências}

AGAMBEN, Giorgio. Meios sem fim: Notas sobre a política. Belo Horizonte: Autêntica, 2015. AMADIUME, Ifi. Reiventing Africa: Matriarchy, religion and culture. London/New York: Zed Book, 2001.

BASTIDE, Roger. As religiões africanas no Brasil: Contribuições a uma sociologia das interpretações de civilizações. São Paulo: Livraria Pioneira Editora, 1989.

BENTO, Maria Aparecida Silva. Branqueamento e branquitude no Brasil. In: CARONE, Iray; BENTO, Maria Aparecida Silva. Psicologia Social Do Racismo - Estudos Sobre Branquitude e Branqueamento no Brasil. Petrópolis: Vozes, 2002, p. 25-58.

\footnotetext{
${ }^{56}$ PRANDI, Mitologia dos orixás, p. 24.

${ }^{57}$ NTUMBA, Le réel comme procès multiforme : pour une philosophie du Nous processuel, englobant et plural, 2014.

${ }^{58}$ MALOMALO, Bioepistemolologia do Ntu: Meu(s) diálogo(s) com Dagoberto José Fonseca, 2018.
} 
BERNARDINO-COSTA, Joaze; MALDONADO-TORRES, Nelson; GROSFOGUEL, Ramón (Orgs.). Decolonialidade e pensamento afrodiaspórico. Belo Horizonte: Autêntica, 2018.

BILOLO, Mubabingue. Les cosmo-théologiques philosophiques de l'Égypte antique:

Problématiques-prémisses hermenêutiques-et-problèmes majeurs. Kinshasa, Libreville, Munich: Publications Universitaires Africaines/Académie de la Pensée Africaine, 1986.

BOURDIEU, Pierre. Les règles de l'art: Genèse et structure du champ littéraire. Paris: Édition du Seuil, 1998.

CAVALCANTE, Paulo Sérgio Lisboa; JESUS, Aurilene Pereira de. Sabedoria e ancestralidade no Ceará: A didática dos tambores à sombra da pedagogia do baobá. In: PETIT, Sandra Haydée e SILVA, Geranilde Costa e (Orgs.). Memórias de Baobás. Fortaleza: Edições UFC, 2012, p. 199-212.

DICIO: Dicionário online. Disponível em: http://www.dicio.com.br/cambondo/. 2009. Acessado em: 15 jan. 2014.

FAIK-NZUGI. Arts africains. Signes et symboles. Louvain-la-Neuve: De Boeck Université, 2000.

FERNANDES, Florestan. A integração do negro na sociedade de classes: no limiar de uma nova era. Vol 2, São Paulo: Ática, 1978.

FLAUZINA, Ana Luiza Pinheiro. Corpo negro caído no chão: O sistema penal e o projeto genocídio do Estado brasileiro. Brasília: Brado Negro, 2017.

FLAUZINA, Ana Luiza Pinheiro; VARGAS, João Helion Costa. Motim: Horizontes do genocídio antinegro na Diáspora. Brasília: Brado Negro, 2017.

KILEUY, Odé; OXAGUIÃ, Vera. O Candomblé bem explicado (nações bantu, ioruba e fon). Rio de Janeiro: Pallas, 2009.

LOPES, Nei. Dicionário escolar afro-brasileiro. São Paulo: Selo Negro, 2006.

LOPES, N. Enciclopédia brasileira: Diáspora africana. São Paulo: Selo Negro, 2004.

MALOMALO, Bas' Ilele. Bioepistemolologia do Ntu: Meu(s) diálogo(s) com Dagoberto José Fonseca. In: FONSECA, Dagoberto José; MALOMALO, Bas' Ilele; FERREIRA, Simone Loiola (Orgs.). Intelectualidade coletiva negra: memórias, educação e emancipação. Porto Alegre: Editora Fi, 2018, p. 69-120.

MALOMALO, Bas' Ilele. Macumba, macumbização e desmacumbização. In: SILVEIRA, Ronie Alexsandro Teles da; LOPES, Marcos Carvalho (Orgs.) A religiosidade brasileira e a filosofia. Porto Alegre, RS: Editora Fi, 2016b, p. 132-160.

MALOMALO, Bas'Ilele. Retrato dos brancos/as antirracistas feito do ponto de vista de uma educação macumbista. In: MULLER, Tânia; CARDOSO, Lourenço. Branquitude: estudos sobre identidade branca no Brasil. Curitiba: Appris, 2017c, p. 259-276. 
MBEMBE, Achille. Necropolítica/Sobre el gobierno privado indirecto. Trad Elisabeth Falomir. Santa Cruz de Tenerife: Editorial Melusina, 2011.

MBEMBE, A. Crítica da razão negra. Lisboa: Antígonas, 2014.

MOORE, Carlos. Racismo e sociedade: novas bases epistemológicas para entender o racismo. Belo Horizonte: Mazza, 2007.

MVENG, Engelbert. L'art d'Afrique noire: liturgie cosmique et langage religieux. Yaoundé: Clé, 1974.

MVENG, E. Problematique d'une estétique negro-africaine. Ethiopiques - revue socialiste de la culture négro-africane, n. 03, p. 1-7, jul. 1973. Disponível em:

http://ethiopiques.refer.sn/spip.php?page=imprimer-article\&id_article=490. Acessado em 21 fev. 2014.

NAKOULIMA, Pierre Gomdraogo. A crise ecológica como exigência de um novo paradigma. In: HOUNTONDJI, Paulin. O antigo e o moderno. A produção do saber na África Contemporânea. Luanda: Pedago/Mulemba, 2012, p. 83-98.

NASCIMENTO, Abdias do. O Genocídio do Negro Brasileiro: Processo de um Racismo Mascarado. Rio de Janeiro: Paz e Terra, 1978.

NATÁLIA, Lívia. Sobejos do mar. Salvador: Camurê, 2017.

NTUMBA, Tshamalenga M. Le réel comme procès multiforme: pour une philosophie du Nous processuel, englobant et plural. Paris: Edilivre-Aparis, 2014.

OBENGA, Théophile. La philosophie africaine de la période pharaonique, 2780-330 avant notre ère. Paris: L' Harmattan, 1999.

OYEWUMI, Oyeronke. The invention of Woman: Making na african sense of wester gender discourses. Mineapolis: University of Minnesota Press, 1997.

PESSANHA, Eliseu Amaro de Melo; NASCIMENTO, Wanderson Flor. Necropolítica: Estratégia do extermínio do corpo negro. Odeere: Revista do Programa de Pós-Graduação em Relações Étnicas e Contemporaneidade - UESB, v. 3, n. 6, p. 149-177, Jul-Dez 2018.

PRANDI, Reginaldo. Mitologia dos orixás. São Paulo: Companhia das Letras, 2001.

RAMOS, Guerreiro. Introdução crítica à sociologia brasileira. Rio de Janeiro: Editora UFRJ, 1995.

RIVIÈRE, Claude. As liturgias políticas. Rio de Janeiro: Imago, 1989.

SODRÉ, Muniz. Pensar nagô. Petrópolis: Editora Vozes, 2017.

SODRÉ, M. A verdade seduzida: Por um conceito de cultura no Brasil. Rio de Janeiro: DP \& A editora, 2005.

THÉSÉE, Gina. L’interculturel en environnement: Rencontre de la justice sociale et de la justice environnementale. Canadian and International Education, v. 37, n. 1, p. 45-70, Jun 2008. 
TRINDADE, Solano. Poemas antológicos. São Paulo: Editora Nova Alexandria, 2007.

VERGER, Pierre Fatumbi. Orixás: Deuses iorubas na África e no novo mundo. Salvador: Corrupio, 2002. 